Article

\title{
Benign Convulsions with Mild Rotavirus and Norovirus Gastroenteritis: Nationwide Data from the Health Insurance Review and Assessment Service in South Korea
}

\author{
Dong Hyun Kim ${ }^{+}\left(\mathbb{D}\right.$, Dong Jun Ha ${ }^{+} \mathbb{D}$, Yeong Seok Lee $\mathbb{D}^{\mathbb{D}}$, Min Jun Chun $\mathbb{D}^{\mathbb{D}}$ and Young Se Kwon *(D) \\ Department of Pediatrics, Inha University School of Medicine, Incheon 22332, Korea; id@inha.ac.kr (D.H.K.); \\ djha0917@inhauh.com (D.J.H.); yslee1016@inhauh.com (Y.S.L.); mjchun0716@inhauh.com (M.J.C.) \\ * Correspondence: ysped@inha.ac.kr; Tel.: +82-32-890-3579 \\ † These authors contributed equally to this work.
}

check for

updates

Citation: Kim, D.H.; Ha, D.J.; Lee, Y.S.; Chun, M.J.; Kwon, Y.S. Benign Convulsions with Mild Rotavirus and Norovirus Gastroenteritis:

Nationwide Data from the Health Insurance Review and Assessment Service in South Korea. Children 2021, 8, 263. https://doi.org/10.3390/ children 8040263

Academic Editor: Jim Buttery

Received: 4 March 2021

Accepted: 29 March 2021

Published: 30 March 2021

Publisher's Note: MDPI stays neutral with regard to jurisdictional claims in published maps and institutional affiliations.

Copyright: (C) 2021 by the authors. Licensee MDPI, Basel, Switzerland. This article is an open access article distributed under the terms and conditions of the Creative Commons Attribution (CC BY) license (https:/ / creativecommons.org/licenses/by/ $4.0 /)$.

\begin{abstract}
There have been no large-scale studies on the epidemiology of benign convulsions with mild gastroenteritis $(\mathrm{CwG})$ since the introduction of the rotavirus vaccine in South Korea in 2007. This study aimed to analyze the trends in rotavirus gastroenteritis (RVGE) and rotavirus-associated CwG (RaCwG) after rotavirus vaccination. Further, we aimed to analyze changes in norovirus gastroenteritis (NVGE) and norovirus-associated CwG (NaCwG) using nationwide data from the Korean Health Insurance Review and Assessment Service. Between 2007 and 2019, this study analyzed children aged $<6$ years who were diagnosed with RVGE, NVGE, RaCwG and NaCwG. The changes in the prevalence of each disease and the ratio of $\mathrm{CwG}$ to enteritis were analyzed and the effects of age, sex and season were also analyzed. RVGE, RaCwG, NVGE and NaCwG were diagnosed in 273,898, 4246, 35,593 and 337 patients, respectively. The prevalence of RVGE was on a decreasing trend every year, but the prevalence of NaCwG and NVGE was on an increasing trend. There was a significant annual increase in the ratio of $\mathrm{CwG}$ to enteritis in both viruses. In order to control the prevalence of $\mathrm{RaCwG}$, measures other than the rotavirus vaccine are required and measures to prevent norovirus are necessary.
\end{abstract}

Keywords: rotavirus infection; norovirus infection; benign convulsions with mild gastroenteritis

\section{Introduction}

Annually, more than 100 million individuals present with infectious enteritis with some children requiring hospitalization. Rotavirus and norovirus, which are the major causes of infectious enteritis, are responsible for 520,000 and 200,000 annual deaths, respectively, in children aged $<5$ years [1,2]. Rotavirus and norovirus are transmitted through the fecal-oral route; moreover, it causes fever or intestinal symptoms, including vomiting and diarrhea [3]. In addition, there are some reports that rotavirus and norovirus can cause neurological disorders, including meningitis, encephalitis and encephalopathy [4-6].

Benign convulsions with mild gastroenteritis $(\mathrm{CwG})$ is a neurological disorder caused by an enteric virus and was first described in 1982 by Morooka in children aged 1 month to 6 years without a history of convulsive disease in the absence of fever [7]. Komori reported the following CwG characteristics [8,9]: (1) occurrence of afebrile convulsions within 5 days of acute viral enteritis in a previously healthy child; (2) absence of moderate/severe dehydration; (3) no abnormality in the cerebrospinal fluid test, serum electrolyte level and blood sugar level; (4) good prognosis; and (5) acute illness. Although CwG is often reported in East Asian countries, including South Korea and Japan, it has also been reported in the United States and Europe [10-12].

In 2019, the World Health Organization recommended that all countries include rotavirus vaccines in the National Immunization Program [13]. In South Korea, RotaTeq ${ }^{\circledR}$ and Rotarix®were introduced in June 2007 and March 2008, respectively. Subsequently, 
there has been an annual increase in the rotavirus vaccination rates of South Korean infants born in 2007 (5.1\%), 2008 (26.1\%), 2011 (45.2\%) and 2017 (85.6\%) [14].

Currently, there are clinical studies on several norovirus vaccines, including oral monovalent vaccines and bivalent intramuscular vaccines $[15,16]$. However, there is no commercially available norovirus vaccine.

Since the rotavirus vaccine was introduced, there has been an overall decrease in the prevalence of rotavirus gastroenteritis (RVGE); in contrast, the prevalence of norovirus gastroenteritis (NVGE) has annually increased and has become a major enteric virus [17-20]. However, there have been limited national epidemiological studies for rotavirus-associated $\mathrm{CwG}(\mathrm{RaCwG})$ and norovirus-associated $\mathrm{CwG}(\mathrm{NaCwG})$.

This study aimed to use post-vaccination data from the National Health Insurance Review and Assessment Service (HIRA) database to determine changes in the prevalence of RVGE, NVGE, RaCwG and $\mathrm{NaCwG}$, as well as seasonal changes in the ratio of $\mathrm{RaCwG}$ to RVGE and $\mathrm{NaCwG}$ to NVGE, after the introduction of the rotavirus vaccine.

\section{Materials and Methods}

\subsection{Data Sources}

National Health Insurance covers the entire population of South Korea [21]; consequently, it contains $>98 \%$ of national medical information [22]. Using the HIRA database, medical researchers can access diagnostic codes and de-identified patient medical records. This study employed the HIRA database to determine the number of patients who visited a clinic or hospital with a diagnosis of RVGE, RaCwG, NVGE and RaCwG. Subsequently, we used the mid-year population (MYP) obtained from the Korean Statistical Information Service (KOSIS) to identify changes in annual prevalence, as well as to compare the prevalence rates over specific periods. This study was approved by the Institutional Review Board of Inha University Hospital (IRB no. 2020-01-036).

\subsection{Patient Criteria}

We obtained medical records of patients aged $<6$ years between 2007 and 2019. Since data for 2019 were only available until May, we only included the data for 2018.

In South Korea, when diagnosing viral enteritis, a diagnosis code corresponding to the related viral enteritis is usually input when positive in Reverse transcription polymerase chain reaction (RT-PCR) or enzyme linked immunoassay (ELISA). Taking this into account, we considered patients with RVGE and NVGE as those with diagnostic ICD-10 codes of A08.0 and A08.11, respectively. Among these patients, we excluded patients diagnosed with "acute gastroenteropathy" (A08.1), "adenoviral enteritis" (A08.2), "viral gastroenteritis" (A08.30) and "astroviral gastroenteritis" (A08.31).

Among RVGE and NVGE patients, those who met the CwG criteria were classified as $\mathrm{RaCwG}$ and NaCwG, respectively; moreover, cases with "convulsion" (R56) and "other and unspecified convulsions" (R56.8) were included. Additionally, for newborns aged $<29$ days, cases with "convulsion of newborn" (P90) were included. Based on the criteria described by Komori et al. [9], we excluded patients with the following diagnostic codes: (1) "febrile convulsions" (R56.0); (2) "dehydration" (P74, E86); "disorders of fluid, electrolyte and acid-base balance" (E87) or "hypoglycemia" (E16, P70); (3) "meningitis" (A87, G00, G01, G02, G03); "encephalitis" (B00.4, A83, A84, A85, G04, G05); and (4) "epilepsy" (G40).

\subsection{Analysis of Changes in the Prevalence of RaCwG, RVGE, NaCwG and NVGE}

To calculate the annual incidence per 100 individuals of RaCwG, RVGE, NaCwG and NVGE, the number of patients having each disease relative to the MYP from 2007 to 2018 were used. In addition, as the rotavirus vaccination rate increased [14], the trend of annual changes in the incidence of $\mathrm{RaCwG}$ and RVGE was identified. In order to analyze this change according to the rotavirus inoculation rate, the period was divided into period $\mathrm{A}$ (2007-2012) and period B (2012-2018), as 2012 was five years after the introduction of the rotavirus vaccine in South Korea. The prevalence of rotavirus was compared. 
To analyze the effect of additional factors on the prevalence of RaCwG, RVGE, NaCwG and NVGE, the incidence of disease was separated by age, sex and season.

\subsection{Analysis of the Ratio of CwG to RVGE or NVGE}

By calculating the ratio of RaCwG to RVGE and the ratio of NaCwG to NVGE per year, the change in the incidence of $C w G$ patients among enteritis patients was analyzed. To analyze the effect of additional factors on the ratio of RaCwG to RVGE and the ratio of $\mathrm{NaCwG}$ to NVGE, we analyzed by age, sex and season.

\subsection{Statistical Analysis}

Data analysis was performed with remote access to the HIRA database using SAS Enterprise version 9.2 (SAS Institute, Cary, NC, USA). Statistical analyses were performed using SPSS version 19.0 (IBM, Armonk, NY, USA). Using negative binomial regression anlaysis, annual prevalence changes of $\mathrm{RaCwG}$, RVGE, $\mathrm{NaCwG}$ and NVGE and changes in prevalence according to age, sex and season were analyzed. Furthermore, using negative binomial regression analysis, not only were the annual change of the ratio of $\mathrm{RaCwG}$ to RVGE and the ratio of NaCwG to NVGE examined, but also the change according to age, sex and season were analyzed. Prevalence changes in periods A and B were analyzed using chi-square analysis. Statistical significance was set at $p<0.05$.

\section{Results}

\subsection{Characteristics of Patients with RVGE, RaCwG, NVGE and NaCwG}

Between 2007 and 2018, there were 273,898 and 35,593 patients with RVGE and NVGE, respectively. Among them, 4246 and 337 patients had $\mathrm{RaCwG}$ and $\mathrm{NaCwG}$, respectively. Patients with RVGE (37.8\%) and RaCwG (63.1\%) accounted for the highest proportions in the $<1$-year-old group. Further, patients with NVGE $(30.0 \%)$ and NaCwG $(59.9 \%)$ accounted for the highest proportions in the 1-2-years-old group. Additionally, patients with NVGE $(44.5 \%)$ and $\mathrm{NaCwG}(50.4 \%)$ accounted for the highest proportions during winter. In the 1-2-years-old group, the mean prevalence of $\mathrm{RaCwG}$ and $\mathrm{NaCwG}$ per 100 comprising the MYP was 0.013 and 0.00001 , respectively.

The ratio of male and female was $54.8 \%$ and $45.2 \%$ in patients with RVGE, $52.1 \%$ and $47.9 \%$ in patients with $\mathrm{RaCwG}, 54.6 \%$ and $45.4 \%$ in patients with NVGE and $45.4 \%$ and $54.6 \%$ in patients with $\mathrm{NaCwG}$, respectively (Table 1 ).

Table 1. Characteristics of patients with rotavirus gastroenteritis (RVGE), rotavirus-associated benign convulsion with mild gastroenteritis $(\mathrm{RaCwG})$, norovirus gastroenteritis (NVGE) and norovirusassociated $\mathrm{CwG}(\mathrm{NaCwG})$.

\begin{tabular}{ccccc}
\hline & RVGE & RaCwG & NVGE & NaCwG \\
\hline $\begin{array}{c}\text { Subjects } \\
\text { Sex }\end{array}$ & 273,898 & 4246 & 35,593 & 337 \\
Male & $150,150(54.8)$ & $2211(52.1)$ & $19,439(54.6)$ & $153(45.4)$ \\
Female & $123,748(45.2)$ & $2035(47.9)$ & $16,154(45.4)$ & $184(54.6)$ \\
Age (years) & & & & \\
$<1$ & $103,616(37.8)$ & $2681(63.1)$ & $7905(22.2)$ & $47(13.9)$ \\
1 & $76,690(28.0)$ & $974(23.0)$ & $10,638(30.0)$ & $202(59.9)$ \\
2 & $39,279(14.3)$ & $376(8.9)$ & $5901(16.6)$ & $48(14.2)$ \\
3 & $24,970(9.1)$ & $115(2.7)$ & $4215(11.8)$ & $14(4.2)$ \\
4 & $17,122(6.3)$ & $60(1.4)$ & $3611(10.1)$ & $17(5.0)$ \\
5 & $12,221(4.5)$ & $40(0.9)$ & $3323(9.3)$ & $9(2.7)$ \\
\hline Season & & & & \\
Spring & $94,912(34.7)$ & $1211(28.5)$ & $8508(23.9)$ & $72(21.4)$ \\
Summer & $43,350(15.8)$ & $833(19.6)$ & $4676(13.1)$ & $46(13.6)$ \\
Autumn & $44,694(16.3)$ & $805(19.0)$ & $6560(18.4)$ & $49(14.5)$ \\
Winter & $90,942(33.2)$ & $1397(32.9)$ & $15,849(44.5)$ & $170(50.4)$ \\
\hline
\end{tabular}


Table 1. Cont.

\begin{tabular}{ccccc}
\hline \multicolumn{1}{c}{ RVGE } & RaCwG & NVGE & NaCwG \\
\hline Year & & & & \\
2007 & $47,173(17.2)$ & $501(11.8)$ & $1420(4.0)$ & 0 \\
2008 & $41,619(15.2)$ & $518(12.2)$ & $1107(3.1)$ & 0 \\
2009 & $34,556(12.6)$ & $327(7.7)$ & $513(1.4)$ & 0 \\
2010 & $31,232(11.4)$ & $293(6.7)$ & $937(2.6)$ & $2(0.6)$ \\
2011 & $26,843(9.8)$ & $419(9.8)$ & $1059(3.0)$ & $1(0.3)$ \\
2012 & $20,472(7.5)$ & $392(9.2)$ & $1377(3.9)$ & 0 \\
2013 & $18,074(6.6)$ & $312(7.3)$ & $1978(5.5)$ & $4(1.2)$ \\
2014 & $12,778(4.7)$ & $282(6.6)$ & $2257(6.3)$ & $13(3.9)$ \\
2015 & $12,614(4.6)$ & $317(7.5)$ & $3047(8.6)$ & $16(4.7)$ \\
2016 & $8949(3.2)$ & $267(6.3)$ & $6767(19.0)$ & $71(21.0)$ \\
2017 & $10,907(4.0)$ & $282(6.6)$ & $7954(22.3)$ & $99(29.4)$ \\
2018 & $8681(3.1)$ & $337(7.9)$ & $7177(20.2)$ & $131(38.9)$
\end{tabular}

RVGE: rotavirus gastroenteritis, RaCwG: rotavirus-associated benign convulsion with mild gastroenteritis, NVGE: Norovirus gastroenteritis, $\mathrm{NaCwG}$ : norovirus-associated benign convulsion with mild gastroenteritis. Values are presented as the number of patients (\%). Bold to make it easier to distinguish variables.

\subsection{Annual Changes in the Prevalence of RaCwG, RVGE, NaCwG and NVGE}

Although the rotavirus inoculation rate increased every year, the prevalence of $\mathrm{RaCwG}$ did not show any statistically significant change, but the prevalence of $\mathrm{NaCwG}$ increased by 1.790 times each year $(p<0.001)$ (Table 2$)$. Furthermore, in all years of the study period, the prevalence of $\mathrm{RaCwG}$ was higher than that of $\mathrm{NaCwG}$ (Figure 1).

Table 2. Negative binomial regression analysis of patients with $\mathrm{RaCwG}$, patients with $\mathrm{NaCwG}$ and the mid-year population (MYP).

\begin{tabular}{|c|c|c|c|c|c|c|}
\hline & \multicolumn{3}{|c|}{ RaCwG/MYP } & \multicolumn{3}{|c|}{ NaCwG/MYP } \\
\hline & $\operatorname{Exp}(B)$ & $95 \%$ CI & $p$ Value & $\operatorname{Exp}(B)$ & $95 \%$ CI & $p$ Value \\
\hline \multicolumn{7}{|l|}{ Age } \\
\hline$<1$ & 1 & Reference & & 1 & Reference & \\
\hline $1 \sim 2$ & 343 & $0.319-0.369$ & $<0.001 *$ & 3.802 & $2.768-5.223$ & $<0.001$ * \\
\hline $2 \sim 3$ & 0.131 & $0.117-0.146$ & $<0.001 *$ & 0.850 & $0.569-1.271$ & 0.429 \\
\hline $3 \sim 4$ & 0.04 & $0.033-0.048$ & $<0.001$ * & 0.242 & $0.133-0.440$ & $<0.001^{*}$ \\
\hline $4 \sim 5$ & 0.02 & $0.016-0.026$ & $<0.001 *$ & 0.289 & $0.166-0.504$ & $<0.001$ * \\
\hline $5 \sim 6$ & 0.013 & $0.010-0.018$ & $<0.001 *$ & 0.148 & $0.073-0.303$ & $<0.001^{*}$ \\
\hline Year & 0.956 & $0.894-1.022$ & 0.19 & 1.790 & $1.683-1.904$ & $<0.001 *$ \\
\hline Sex (female) & 0.921 & $0.867-0.978$ & 0.007 * & 1.539 & $0.521-4.546$ & 0.435 \\
\hline \multicolumn{7}{|l|}{ Season } \\
\hline Spring & 1 & Reference & & 1 & Reference & \\
\hline Summer & 0.704 & $0.314-1.577$ & 0.394 & 0.582 & $0.166-2.045$ & 0.399 \\
\hline Fall & 0.677 & $0.302-1.517$ & 0.343 & 1.081 & $0.300-3.891$ & 0.906 \\
\hline Winter & 1.139 & $0.510-2.546$ & 0.751 & 4.184 & $1.271-13.77$ & 0.019 * \\
\hline
\end{tabular}

RaCwG/MYP: Number of patients with rotavirus-associated benign convulsions with mild gastroenteritis compared with the mid-year population. NaCwG/MYP: Number of patients with norovirus-associated benign convulsions with mild gastroenteritis compared with the mid-year population. CI: Confidence interval. ${ }^{*} p<0.05$. Bold to make it easier to distinguish variables.

The prevalence of RVGE decreased 0.869 times each year $(p<0.001)$. However, the prevalence of NVGE increased by 1.224 times each year $(p<0.001$ ) (Table 3$)$. The prevalence of RVGE was higher than that of NVGE in all years of the study period (Figure 1).

Regarding the comparison between periods $\mathrm{A}$ and $\mathrm{B}$, the RVGE, RaCwG, $\mathrm{NaCwG}$ and NVGE prevalence per 100 of the MYP changed significantly from 1.20 to $0.45,0.015$ to 0.01 , 0.000018 to 0.002 and 0.04 to 0.18 , respectively, $(p<0.001)$ (Figure 2). 


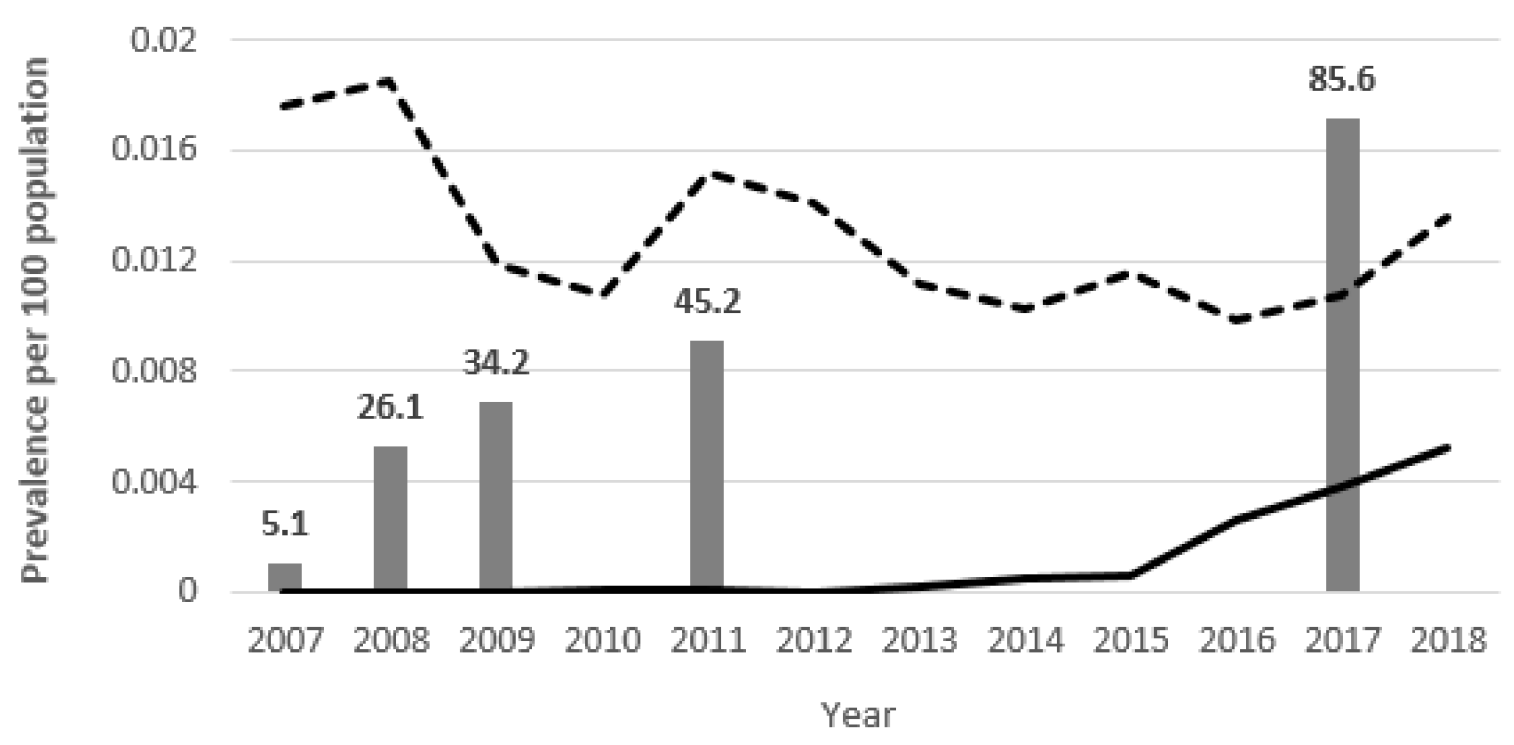

Vaccination rate ---RaCwG $\mathrm{NaCwG}$

(a)

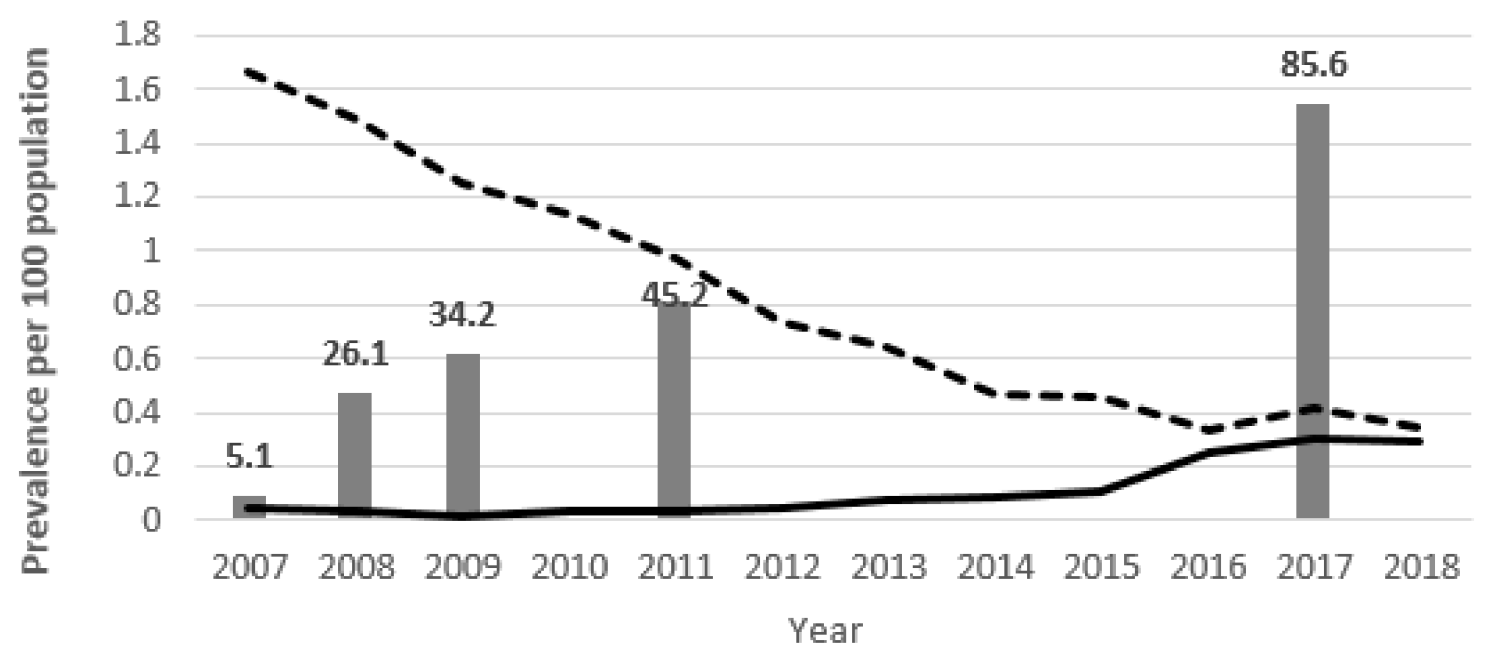

Vaccination rate ---RVGE $\longrightarrow$ NVGE

(b)

Figure 1. Annual changes of the prevalence of rotavirus gastroenteritis (RVGE), rotavirus-associated benign convulsion with mild gastroenteritis ( $\mathrm{RaCwG}$ ), norovirus gastroenteritis (NVGE) and norovirus gastroenteritis (NaCwG) and the vaccination rate. (a) Annual changes of the RaCwG prevalence per 100 comprising the mid-year point (MYP) $(\operatorname{Exp}(\mathrm{B}): 0.956, p=0.190)$ and $\mathrm{NaCwG}$ patients per 100 comprising the MYP $(\operatorname{Exp}(\mathrm{B}): 1.790, p<0.001)$. (b) Annual changes of the prevalence of RVGE $(\operatorname{Exp}(\mathrm{B}): 0.869, p<0.001)$ and NVGE $(\operatorname{Exp}(\mathrm{B}): 1.224, p<0.001)$ per 100 comprising the MYP. 
Table 3. Negative binomial regression analysis of patients with RVGE, patients with NVGE and the MYP.

\begin{tabular}{|c|c|c|c|c|c|c|}
\hline & \multicolumn{3}{|c|}{ RVGE/MYP } & \multicolumn{3}{|c|}{ NVGE/MYP } \\
\hline & $\operatorname{Exp}(B)$ & $95 \%$ CI & $p$ Value & $\operatorname{Exp}(B)$ & $95 \%$ CI & $p$ Value \\
\hline \multicolumn{7}{|l|}{ Age } \\
\hline$<1$ & 1 & Reference & & 1 & Reference & \\
\hline $1 \sim 2$ & 0.624 & $0.280-1.393$ & 0.250 & 1.227 & $1.192-1.264$ & $<0.001$ * \\
\hline $2 \sim 3$ & 0.339 & $0.152-0.755$ & $0.008 *$ & 0.656 & $0.635-0.679$ & $<0.001 *$ \\
\hline $3 \sim 4$ & 0.219 & $0.098-0.487$ & $<0.001$ * & 0.461 & $0.444-0.478$ & $<0.001^{*}$ \\
\hline $4 \sim 5$ & 0.156 & $0.070-0.348$ & $<0.001$ * & 0.39 & $0.375-0.406$ & $<0.001$ * \\
\hline $5 \sim 6$ & 0.113 & $0.051-0.251$ & $<0.001$ * & 0.353 & $0.339-0.367$ & $<0.001^{*}$ \\
\hline Year & 0.869 & $0.814-0.938$ & $<0.001$ * & 1.224 & $1.176-1.273$ & $<0.001 *$ \\
\hline Sex (female) & 0.846 & $0.755-0.949$ & $0.004^{*}$ & 0.833 & $0.374-1.855$ & 0.654 \\
\hline \multicolumn{7}{|l|}{ Season } \\
\hline Spring & 1 & Reference & & 1 & Reference & \\
\hline Summer & 0.201 & $0.201-0.995$ & 0.049 * & 0.568 & $0.255-1.266$ & 0.167 \\
\hline Fall & 0.196 & $0.196-0.972$ & $0.042 *$ & 0.73 & $0.327-1.628$ & 0.442 \\
\hline Winter & 0.402 & $0.402-1.992$ & 0.784 & 1.759 & $0.789-3.922$ & 0.167 \\
\hline
\end{tabular}

RVGE/MYP: Number of patients with rotavirus gastroenteritis compared with the mid-year population. NVGE/MYP: Number of patients with norovirus gastroenteritis compared with the mid-year population. CI: Confidence interval. ${ }^{*} p<0.05$. Bold to make it easier to distinguish variables.

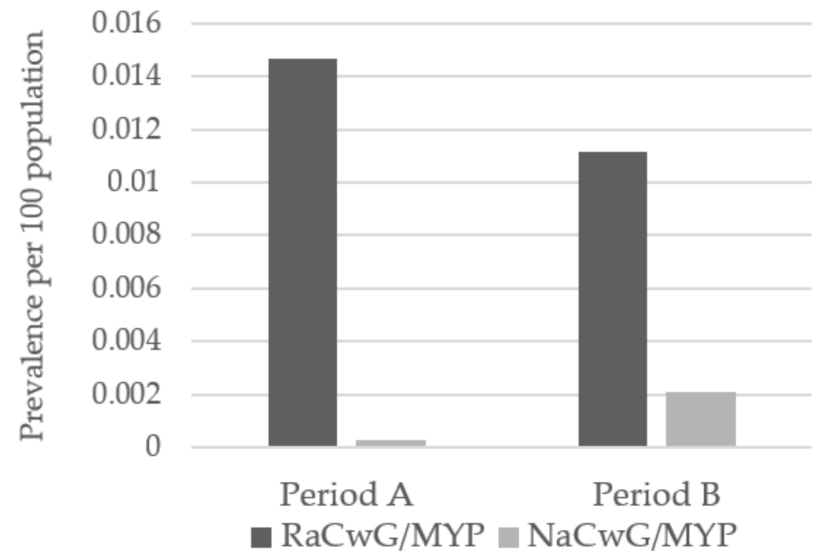

(a)

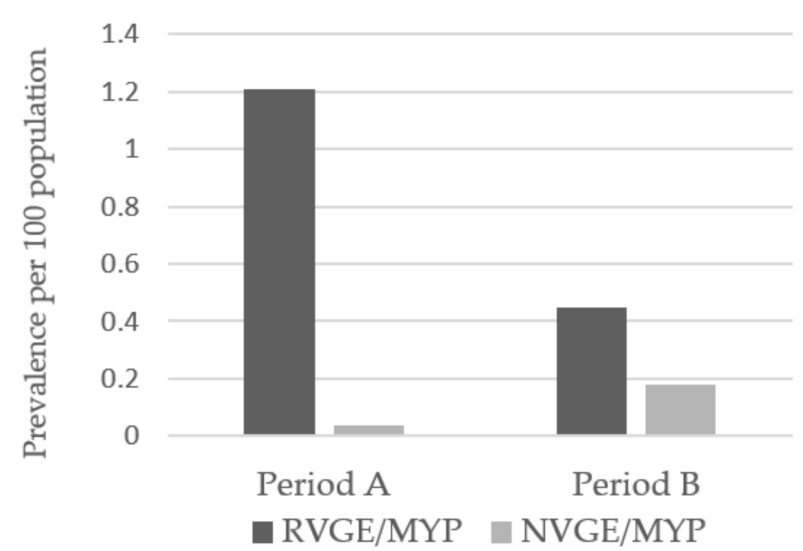

(b)

Figure 2. Between-period comparison of the prevalence of RVGE, RaCwG, NVGE and NaCwG. (a) Comparison of the RaCwG prevalence per 100 comprising the MYP (odds ratio: 0.759, $p<0.001$ ) and NaCwG patients per 100 comprising the MYP (odds ratio: 115.311, $p<0.001$ ). (b) Comparison of the prevalence of RVGE (odds ratio: $0.369, p<0.001$ ) and NVGE (odds ratio: $4.713, p<0.001$ ) per 100 comprising the MYP. RVGE: rotavirus gastroenteritis, RaCwG: rotavirusassociated benign convulsion with mild gastroenteritis, NVGE: norovirus gastroenteritis, NaCwG: norovirus-associated benign convulsion with mild gastroenteritis, MYP: mid-year population, Period A: 2007-2012, Period B: $2013-2018$.

\subsection{Annual Changes of the Ratio of CwG to RVGE or NVGE}

There was an annual increase in the ratio of RaCwG to RVGE by $1.104(p=0.004)$. The ratio of NaCwG to NVGE showed a significant annual increase by $1.852(p<0.001)$ (Table 4). In all years of the study period, the ratio of RaCwG to RVGE was higher than the ratio of NaCwG to NVGE (Figure 3). 
Table 4. Negative binomial regression analysis of the patients with RaCwG compared with RVGE; the patients with NaCwG compared with NVGE.

\begin{tabular}{|c|c|c|c|c|c|c|}
\hline & \multicolumn{3}{|c|}{ RaCwG/RVGE } & \multicolumn{3}{|c|}{ NaCwG/NVGE } \\
\hline & $\operatorname{Exp}(B)$ & $95 \%$ CI & $p$ Value & $\operatorname{Exp}(B)$ & $95 \%$ CI & $p$ Value \\
\hline \multicolumn{7}{|l|}{ Age } \\
\hline$<1$ & 1 & Reference & & 1 & Reference & \\
\hline $1 \sim 2$ & 0.494 & $0.220-1.106$ & 0.086 & 4.49 & $1.362-14.798$ & 0.014 * \\
\hline $2 \sim 3$ & 0.365 & $0.163-0.821$ & $0.015 *$ & 0.927 & $0.259-3.315$ & 0.908 \\
\hline $3 \sim 4$ & 0.171 & $0.075-0.391$ & $<0.001 *$ & 0.286 & $0.070-1.171$ & 0.082 \\
\hline $4 \sim 5$ & 0.133 & $0.057-0.309$ & $<0.001 *$ & 0.255 & $0.063-1.033$ & 0.056 \\
\hline $5 \sim 6$ & 0.119 & $0.050-0.282$ & $<0.001 *$ & 0.140 & $0.031-0.630$ & $0.010 *$ \\
\hline Year & 1.104 & $1.032-1.106$ & $0.004 *$ & 2.128 & $1.768-2.560$ & $<0.001$ * \\
\hline Sex (female) & 1.08 & $0.484-2.413$ & 0.851 & 1.852 & $0.627-5.471$ & 0.265 \\
\hline \multicolumn{7}{|l|}{ Season } \\
\hline Spring & 1 & Reference & & 1 & Reference & \\
\hline Summer & 1.542 & $0.688-3.457$ & 0.293 & 1.086 & $0.307-3.838$ & 0.899 \\
\hline Fall & 1.539 & $0.685-3.459$ & 0.297 & 1.384 & $0.385-4.980$ & 0.619 \\
\hline Winter & 1.263 & $0.565-2.822$ & 0.569 & 2.279 & $0.684-7.596$ & 0.180 \\
\hline
\end{tabular}

RaCwG/RVGE: Number of patients with rotavirus-associated benign convulsions with mild gastroenteritis compared with rotavirus gastroenteritis. NaCwG/NVGE: Number of patients with norovirus-associated benign convulsions with mild gastroenteritis compared with norovirus gastroenteritis. CI: confidence interval. ${ }^{*} p<0.05$. Bold to make it easier to distinguish variables.

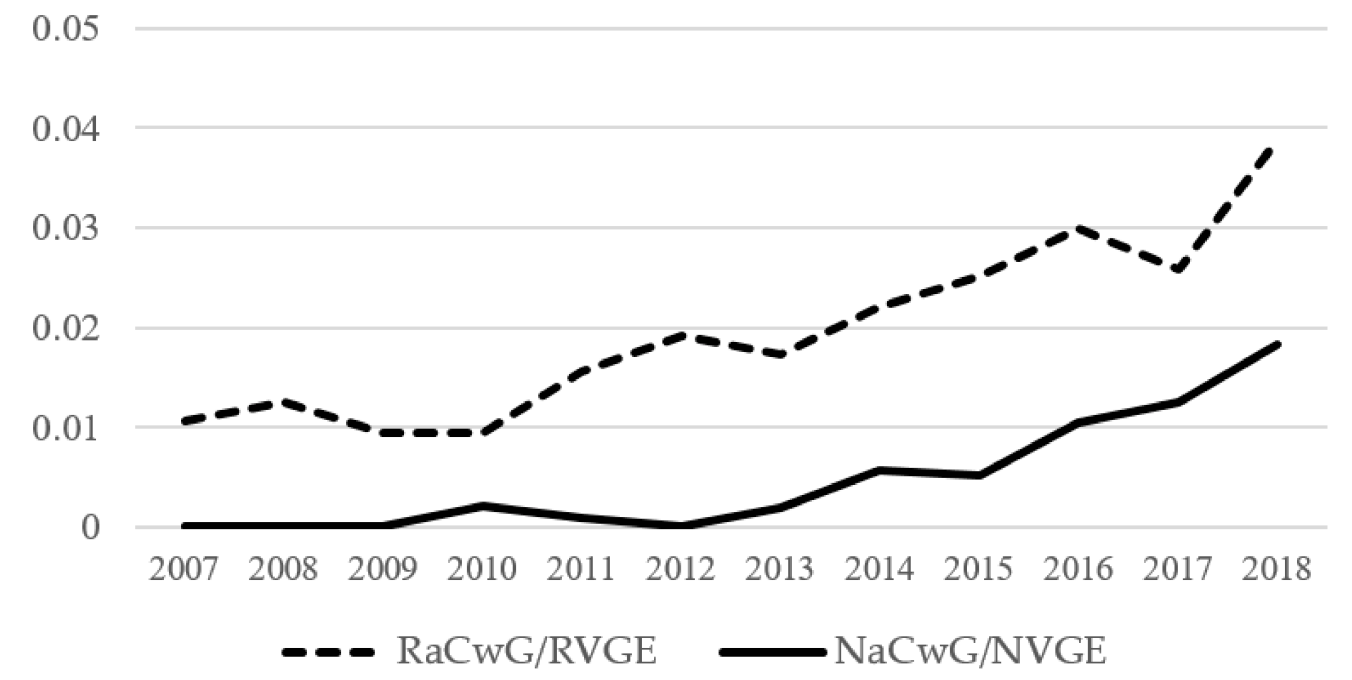

Figure 3. Annual changes in ratio of RaCwG to RVGE $(\operatorname{Exp}(\beta): 1.104$ (95\% CI 1.032-1.182), $p=0.004)$ and ratio of $\mathrm{NaCwG}$ to NVGE $(\operatorname{Exp}(\beta): 1.578$ (95\% CI 1.279-1.948), $p<0.001)$. RVGE: rotavirus gastroenteritis, $\mathrm{RaCwG}$ : rotavirus-associated benign convulsion with mild gastroenteritis, NVGE: norovirus gastroenteritis, $\mathrm{NaCwG}$ : norovirus-associated benign convulsion with mild gastroenteritis.

\subsection{The Prevalence of RaCwG, RVGE, NaCwG, NVGE and the Ratio of CwG to RVGE or NVGE According to Season}

There was no statistically significant difference in the prevalence of $\mathrm{RaCwG}$ and $\mathrm{NaCwG}$ according to the season (Table 2). The incidence of RVGE was significantly less during two seasons, with an odds ratio in summer of $0.201(p=0.049)$ and an odds ratio in autumn of $0.196(p=0.042)$, relative to spring. There was no significant difference in the prevalence of NVGE according to the season (Table 3).

The ratio of $\mathrm{RaCwG}$ to RVGE and the ratio of $\mathrm{NaCwG}$ to NVGE were not significantly different depending on the season (Table 4).

The ratio of RaCwG to RVGE was highest in the summer and autumn in periods $\mathrm{A}$ and B (Figure 4). The ratio was not significantly different in all seasons for period A and period B $(p=0.298)$. 


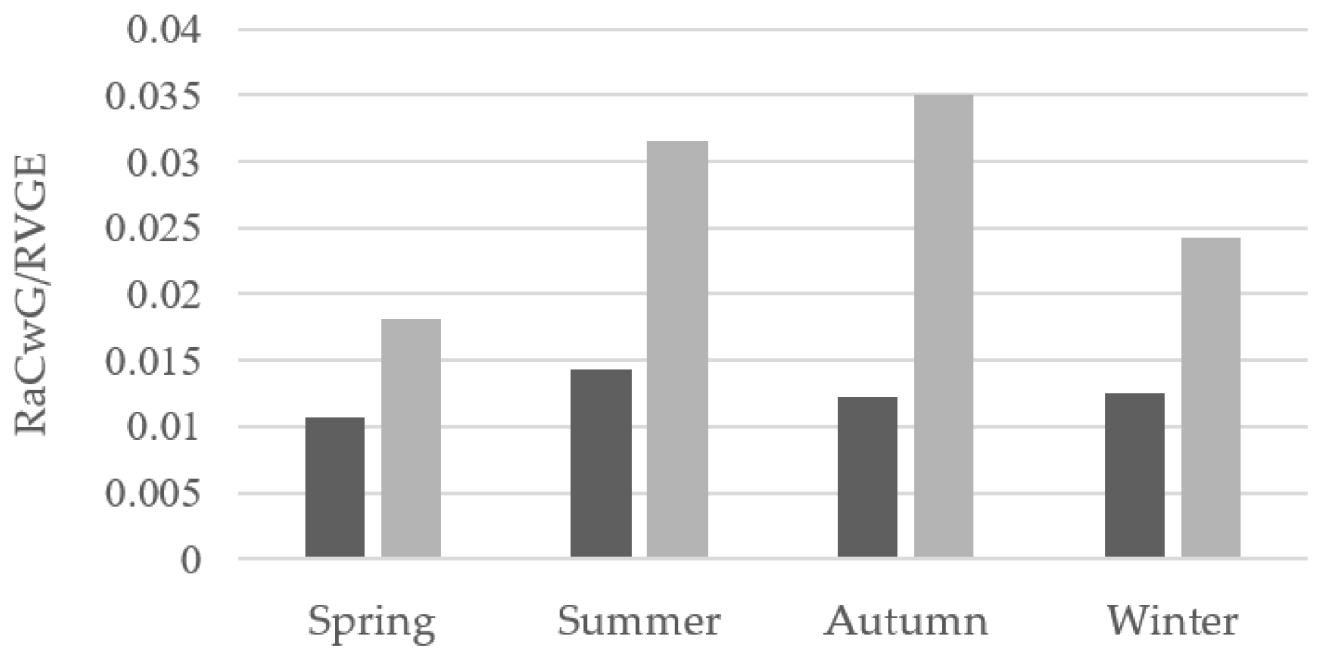

Period A $\square$ Period B

Figure 4. Seasonal between-period comparison of the ratio of RaCwG to RVGE, $p=0.298$. RVGE: rotavirus gastroenteritis, $\mathrm{RaCwG}$ : rotavirus-associated benign convulsion with mild gastroenteritis, Period A: 2007-2012, Period B: 2013-2018.

\subsection{The Prevalence of RaCwG, RVGE, NaCwG, NVGE and the Ratio of CwG to RVGE or NVGE} According to Sex

The prevalence of RaCwG was significantly lower in females than in males and the odds ratio was $0.921(p=0.007)$. However, the prevalence of $\mathrm{NaCwG}$ did not differ significantly according to sex (Table 2). The prevalence of RVGE was significantly lower in females than in males and the odds ratio was $0.846(p=0.004)$. However, the prevalence of NVGE did not show any significant difference according to sex (Table 3).

The ratio of $\mathrm{RaCwG}$ to RVGE and the ratio of $\mathrm{NaCwG}$ to NVGE were not significantly different according to sex (Table 4).

3.6. The Prevalence of $R a C w G, R V G E, N a C w G, N V G E$ and the Ratio of CwG to RVGE or NVGE According to Age

The prevalence of RaCwG was decreased in all age groups from 1 to 6 years old compared to those under 1 year old $(p<0.001)$. Moreover, based on the age group under 1 year old, the odds ratio decreased as the age increased (Table 2).

The prevalence of $\mathrm{NaCwG}$ was significantly higher in the age group between 1 and 2 years old compared to the age group under 1 year old $(p<0.001)$. However, the prevalence was significantly lower in the age group from 3 to 6 years old compared to the age group under 1 year $(p<0.001)$ (Table 2).

The prevalence of RVGE was significantly lower in all age groups between 2 and 6 years of age compared to those under 1 year of age. As the age increased, the odds ratio for those under 1 year old decreased (Table 3).

The prevalence of NVGE was significantly higher in the age group between 1 and 2 years old compared to the age group under 1 year old $(p<0.001)$. However, the prevalence was significantly lower in the age group from 2 to 6 years old compared to the age group under 1 year $(p<0.001)$ (Table 2).

The ratio of $\mathrm{RaCwG}$ to RVGE was significantly lower in all age groups from 2 to 6 years old compared to the age group under 1 year. At this time, the odds ratio was lower as the age group increased. The ratio of $\mathrm{NaCwG}$ to NVGE was significantly lower in all age groups from 5 to 6 years old compared to the age group under 1 year. However, the odds ratio in the age group from 1 to 2 years was higher than that of the age group under 1 year (Table 4). 


\section{Discussion}

Most patients with $\mathrm{CwG}$ do not present with abnormal findings in the cerebrospinal fluid test, blood test and electroencephalogram. Further, there are no convulsions after improvement of digestive symptoms; additionally, anticonvulsants are rarely required since patients show a good long-term prognosis [23]. Therefore, further tests can be avoided through early $\mathrm{CwG}$ diagnosis. Numerous $\mathrm{CWG}$ cases are accompanied by rotavirus infection $[10,24]$. However, the incidence of norovirus, which has recently increased, is higher during winter than other seasons, which consequently affects the $\mathrm{NaCwG}$ prevalence.

In Korea, RotaTeq ${ }^{\circledR}$ was first introduced in 2007; however, since vaccination was not mandatory, the coverage increased after several years. In our study, the RVGE prevalence decreased after the introduction of the rotavirus vaccination, which is consistent with previous reports of a post-vaccination decrease in the prevalence of rotavirus enteritis $[19,25,26]$.

In this study, vaccination affected the decrease in the RVGE prevalence. In addition, as the rotavirus vaccination rate increased, the prevalence of $\mathrm{RaCwG}$ decreased. However, the prevalence of $\mathrm{RaCwG}$ has not been declining every year. A recent study on patients with $\mathrm{RaCwG}$ aged $<3$ years reported a non-significant change in the $\mathrm{RaCwG}$ prevalence after rotavirus vaccination [27]. However, another study on patients aged $<5$ years reported a decrease in the hospitalization rate for convulsions after rotavirus vaccination [28]. In addition, there are studies showing that rotavirus vaccination reduces hospitalization rates for febrile seizures by $38 \%$. This is a case that does not meet the diagnostic criteria for $\mathrm{CwG}$, which is characterized by afebrile convulsion [29], but is a study showing that the rotavirus vaccine reduces the severity of neurological symptoms caused by rotavirus infection. From these results, the prevalence of $\mathrm{RaCwG}$ was influenced by other factors such as the age of the patient group as well as the rotavirus vaccination rate.

In 2006, a new norovirus variant termed GII.4 variant spread through groundwater and infected 2000 students in Korea [30]. Other variants were reported in 2009 and 2012, which led to large-scale diagnostic testing for norovirus [31]. In this study, there was an increase in the prevalence of NVGE and $\mathrm{NaCwG}$ after the introduction of the rotavirus vaccine. Moreover, this appears to reflect the recent trend of an increased norovirus prevalence in Korea [20,32]. Additionally, it is consistent with previous reports of an increase in the NVGE prevalence in Asia, Europe and the United States [33-35]. In Korea, norovirus enteritis was classified as a nationally designated infectious disease in 2011 and specimen surveillance began. Therefore, this may increase the availability of Norovirus diagnostic tests, which may affect the prevalence of NVGE and NaCwG. Wwith these changes, RT-PCR began to be used for the diagnosis of norovirus [36]. RT-PCR tends to have higher sensitivity than ELISA used in the past and this can also be a factor that increases the prevalence of NVGE and $\mathrm{NaCwG}[37,38]$.

We found that RVGE, RaCwG, NVGE and NaCwG showed a higher prevalence in spring and winter, which is consistent with previous findings $[13,17,39]$. There was no significant change in the seasonal ratio of RaCwG to RVGE after rotavirus vaccination, which suggests that the rotavirus vaccination helped lower the $\mathrm{RaCwG}$ prevalence, but not the ratio of $\mathrm{RaCwG}$ to RVGE.

In this study, patients with RVGE and RaCwG had the highest proportions among the $<1$ year group, which is consistent with previous findings [40,41]. Moreover, patients with NVGE and NaCwG had the highest proportions among children aged 1-2, which is consistent with the findings of previous single-center studies [42,43]. In all four diseases, the prevalence of patients decreased with age in the age group of 3 to 6 years old, and the ratio of $\mathrm{RaCwG}$ to RVGE also showed a decreasing trend in the same age group. This is thought to be due to the neurological vulnerability of children in younger age groups [44].

We observed a significant decrease in the $\mathrm{RaCwG}$ prevalence after rotavirus vaccination; however, the ratio of RaCwG to RVGE increased. Therefore, other factors could have contributed to the increased $\mathrm{RaCwG}$ ratio. First of all, rotavirus vaccination not only lowers the prevalence of RVGE, but also reduces the severity of RVGE, which can reduce the frequency of patient visits to the hospital $[45,46]$. Besides, it was recently reported 
that urban areas have a higher $\mathrm{RaCwG}$ prevalence than rural areas [27]. According to the KOSIS data, there has been a gradual increase in the size of the urban population in South Korea. Therefore, factors associated with the residence of the patients may affect the ratio of RaCwG to RVGE and NaCwG to NVGE. Furthermore, uric acid can be used as a diagnostic index for RaCwG; therefore, the effects of uric acid on the ratio of RaCwG to RVGE should be considered [47]. The ratio of NaCwG to NVGE consistently increased regardless of rotavirus vaccination. Thus, since there was an increasing trend in the NVGE prevalence, factors other than the increased number of patients with NVGE contributed to the increased $\mathrm{NaCwG}$ prevalence. There are reports that a family history is associated with the occurrence of $\mathrm{CwG}$, suggesting that genetic factors may influence the prevalence of $\mathrm{CwG}[48,49]$. For example, there are several studies on the effect of mutations in the neuronal sodium channel alpha 1 subunit (SCN1A) gene on the pathogenesis of $\mathrm{CwG}$ [50-52]. During the study period, there was a continuous increasing trend in the ratio of $\mathrm{RaCwG}$ to RVGE; moreover, the ratio of $\mathrm{NaCwG}$ to NVGE showed a similar increase in the non-vaccinated norovirus group. Therefore, it can be considered that vaccination against the enteritis virus does not improve the ratio of $\mathrm{CwG}$ to acute gastroenteritis.

This study has several limitations. First, we could not directly verify the participants' medical records. Specifically, use of the HIRA database alone could not yield specific clinical information regarding the patients, including the type and duration of convulsion; and it was not possible to know exactly how the patient was diagnosed with rotavirus, norovirus enteritis or $\mathrm{CwG}$ associated with this virus. Second, diagnostic codes could be used to differentiate patients. In cases where diagnostic codes were omitted for patients with test results indicative of RVGE or NVGE, the number of patients would have been as low as those excluded from the study. Third, this study did not sufficiently consider the coinfection of rotavirus and norovirus due to technical limitations in the process of using the HIRA database. Because of this, the prevalence of each disease can be calculated higher than it actually is.

Our findings revealed a decrease in the prevalence of RVGE and $\mathrm{RaCwG}$ after rotavirus vaccination. However, NVGE and $\mathrm{NaCwG}$, which were not associated with rotavirus vaccination, showed a continuously increased prevalence. This suggests that rotavirus vaccination is effective for RVGE-caused gastrointestinal symptoms and CwG, which is related to the nervous system. Additionally, it may be helpful in differential diagnosis of seizures for clinicians to keep in mind the possibility of $\mathrm{CwG}$ in children under 2 years of age. There is also a need to develop a norovirus vaccine to reduce the incidence of NVGE and NaCwG. However, since the ratio of RaCwG to RVGE and NaCwG to NVGE continuously increased, further studies are required to identify other factors that increase the progression of $\mathrm{CwG}$ to acute gastroenteritis. Moreover, there is a need to determine whether the prevalence of $\mathrm{CwG}$ continues to increase overall.

Author Contributions: Conceptualization: D.J.H.; Methodology: D.J.H. and Y.S.L.; Data curation: D.J.H. and M.J.C.; Formal analysis: D.H.K.; Validation: D.H.K.; Writing-original draft: Y.S.L.; Writing-review \& editing: Y.S.K. All authors have read and agreed to the published version of the manuscript.

Funding: This research was funded by an Inha University Hospital Research Grant.

Institutional Review Board Statement: The study was conducted according to the guidelines of the Declaration of Helsinki and approved by the Institutional Review Board of Inha University Hospital (IRB no. 2020-01-036).

Informed Consent Statement: Not applicable, for studies on anonymous claim database.

Data Availability Statement: The data are not publicly available.

Acknowledgments: The authors would like to thank all the members of the Korean Society of Pediatric Infectious Diseases and the Korean Child Neurology Society. 
Conflicts of Interest: The authors declare no conflict of interest. The funders had no role in the design of the study; in the collection, analyses, or interpretation of data; in the writing of the manuscript, or in the decision to publish the results.

\section{References}

1. Centers for Disease Control and Prevention. Rotavirus. In Epidemiology and Prevention of Vaccine-Preventable Diseases, 13th ed.; Hamborsky, J., Kroger, A., Wolfe, S., Eds.; Public Health Foundation: Washington, DC, USA, 2015; pp. 311-322.

2. Centers for Disease Control and Prevention. Norovirus Worldwide. December 2017. Available online: https://www.cdc.gov/ norovirus/trends-outbreaks/worldwide.html (accessed on 29 March 2021).

3. Leshem, E.; Lopman, B.A. Viral Gastroenteritis. In Principles and Practice of Pediatric Infectious Diseases, 5th ed.; Long, S.S., Prober, C.G., Fischer, M., Eds.; Elsevier: Philadephia, PA, USA, 2018; pp. 383-387.

4. Wong, V. Acute gastroenteritis-related encephalopathy. J. Child Neurol. 2001, 16, 906-910. [CrossRef]

5. Nakagomi, T.; Nakagomi, O. Rotavirus antigenemia in children with encephalopathy accompanied by rotavirus gastroenteritis. Arch. Virol. 2005, 150, 1927-1931. [CrossRef]

6. Ito, S.; Takeshita, S.; Nezu, A.; Aihara, Y.; Usuku, S.; Noguchi, Y.; Yokota, S. Norovirus-associated encephalopathy. Pediatr. Infect. Dis. J. 2006, 7, 651-652. [CrossRef]

7. Goodgame, R.W. Viral causes of diarrhea. Gastroenterol. Clin. N. Am. 2001, 30, 779-795. [CrossRef]

8. Abe, T.; Kobayashi, M.; Araki, K.; Kodama, H.; Fujita, Y.; Shinozaki, T.; Ushijima, H. Infantile convulsion with mild gastroenteritis. Brain Dev. 2000, 22, 301-306. [CrossRef]

9. Komori, H.; Wada, M.; Eto, M.; Oki, H.; Aida, K.; Fujimoto, T. Benign convulsions with mild gastroenteritis: A report of 10 recent cases detailing clinical varieties. Brain Dev. 1995, 17, 334-337. [CrossRef]

10. Kang, B.; Kwon, Y.S. Benign convulsion with mild gastroenteritis. Korean J. Pediatr. 2014, 57, 304-309. [CrossRef]

11. Lloyd, M.B.; Lloyd, J.C.; Gesteland, P.H.; Bale, J.F., Jr. Rotavirus gastroenteritis and seizures in young children. Pediatr. Neurol. 2010, 42, 404-408. [CrossRef]

12. Durá-Travé, T.; Yoldi-Petri, M.E.; Gallinas-Victoriano, F.; Molins-Castiella, T. Infantile convulsions with mild gastroenteritis: A retrospective study of 25 patients. Eur. J. Neurol. 2011, 18, 273-278. [CrossRef] [PubMed]

13. World Health Organization. Rotavirus vaccines: An update. Wkly. Epidemiol. Rec. 2009, 84, 533-540.

14. Lee, S.G.; Jeon, S.Y.; Park, K.S. Rotavirus vaccine coverage and related factors. J. Korean. Soc. Matern. Child Health 2019, 23, 175-184. [CrossRef]

15. Mattison, C.P.; Cardemil, C.V.; Hall, A.J. Progress on norovirus vaccine research: Public health considerations and future directions. Expert Rev. Vaccines 2018, 17, 773-784. [CrossRef]

16. Kim, L.; Liebowitz, D.; Lin, K.; Kasparek, K.; Pasetti, M.F.; Garg, S.J.; Gottlieb, K.; Trager, G.; Tucker, S.N. Safety and immunogenicity of an oral tablet norovirus vaccine, a phase I randomized, placebo-controlled trial. JCI Insight 2018, 3, e121077. [CrossRef]

17. Shim, J.O.; Chang, J.Y.; Shin, S.; Moon, J.S.; Ko, J.S. Changing distribution of age, clinical severity, and genotypes of rotavirus gastroenteritis in hospitalized children after the introduction of vaccination: A single center study in Seoul between 2011 and 2014. BMC Infect. Dis. 2016, 16, 287. [CrossRef] [PubMed]

18. Park, D.K.; Chung, J.Y. Changes in the outbreak of rotavirus gastroenteritis in children after introduction of rotavirus vaccines: A retrospective study at a tertiary hospital. Korean J. Pediatr. Infect. Dis. 2014, 21, 167-173. [CrossRef]

19. Payne, D.C.; Boom, J.A.; Staat, M.A.; Edwards, K.M.; Szilagyi, P.G.; Klein, E.J.; Selvarangan, R.; Azimi, P.H.; Harrison, C.; Moffatt, M.; et al. Effectiveness of pentavalent and monovalent rotavirus vaccines in concurrent use among US children $<5$ years of age, 2009-2011. Clin. Infect. Dis. 2013, 57, 13-20. [CrossRef]

20. Ahmed, S.M.; Hall, A.J.; Robinson, A.E.; Verhoef, L.; Premkumar, P.; Parashar, U.D.; Koopmans, M.; Lopman, B.A. Global prevalence of norovirus in cases of gastroenteritis: A systematic review and meta-analysis. Lancet Infect. Dis. 2014, 14, 725-730. [CrossRef]

21. Kim, D.S. Introduction: Health of the health care system in Korea. Soc. Work Public Health 2010, 25, 127-141. [CrossRef] [PubMed]

22. Kim, L.; Kim, J.A.; Kim, S. A guide for the utilization of health insurance review and assessment of national patient samples. Epidemiol. Health 2014, 36, e2014008. [CrossRef]

23. Uemura, N.; Okumura, A.; Negoro, T.; Watanabe, K. Clinical features of benign convulsions with mild gastroenteritis. Brain Dev. 2002, 24, 745-749. [CrossRef]

24. Verrotti, A.; Moavero, R.; Vigevano, F.; Cantonetti, L.; Guerra, A.; Spezia, E.; Tricarico, A.; Nanni, G.; Agostinelli, S.; Chiarelli, F.; et al. Long-term follow-up in children with benign convulsions associated with gastroenteritis. Eur. J. Paediatr. Neurol. 2014, 18, 572-577. [CrossRef] [PubMed]

25. Lee, H.S.; Kim, D.Y.; Kim, J.A.; Choi, S.H. The epidemiological trend of rotavirus gastroenteritis in children in a single center from 2004 to 2012: A retrospective study. Korean J. Pediatr. Infect. Dis. 2014, 21, 181-190. [CrossRef]

26. Chung, J.Y.; Kim, M.S.; Jung, T.W.; Kim, S.J.; Kang, J.H.; Han, S.B.; Kim, S.Y.; Rhim, J.W.; Kim, H.M.; Park, J.H.; et al. Detection of rotavirus genotypes in Korea 5 years after the introduction of rotavirus vaccines. J. Korean Med. Sci. 2015, 30, 1471-1475. [CrossRef] [PubMed]

27. Kim, D.H.; Lee, Y.S.; Ha, D.J.; Chun, M.J.; Kwon, Y.S. Epidemiology of rotavirus gastroenteritis and rotavirus-associated benign convulsions with mild gastroenteritis after the introduction of rotavirus vaccines in South Korea: Nationwide data from the Health Insurance Review and Assessment Service. Int. J. Environ. Res. Public Health 2020, 17, 8374. [CrossRef] 
28. Pardo-Seco, J.; Cebey-López, M.; Martinón-Torres, N.; Salas, A.; Gómez-Rial, J.; Rodriguez-Tenreiro, C.; Martinón-Sánchez, J.M.; Martinón-Torres, F. Impact of rotavirus vaccination on childhood hospitalization for seizures. Pediatric Infect. Dis. J. 2015, 34, 769-773. [CrossRef]

29. Sheridan, S.L.; Ware, R.S.; Grimwood, K.; Lambert, S.B. Febrile Seizures in the Era of Rotavirus Vaccine. Pediatric. Infect. Dis. Soc. 2014, 5, 206-209. [CrossRef] [PubMed]

30. Lee, H.; Kim, M.; Lee, J.E.; Lim, M.; Kim, M.; Kim, J.-M.; Jheong, W.H.; Kim, J.; Ko, G. Investigation of norovirus occurrence in groundwater in metropolitan Seoul, Korea. Sci. Total Environ. 2011, 409, 2078-2084. [CrossRef]

31. Cho, H.G.; Lee, S.G.; Kim, J.E.; Yu, K.S.; Lee, D.Y.; Park, P.H.; Yoon, M.H.; Jho, E.H.; Kim, J.; Paik, S.Y. Molecular epidemiology of norovirus GII.4 variants in children under 5 years with sporadic acute gastroenteritis in South Korea during 2006-2013. J. Clin. Virol. 2014, 61, 340-344. [CrossRef]

32. Qi, R.; Huang, Y.-T.; Liu, J.-W.; Sun, Y.; Sun, X.-F.; Han, H.-J.; Qin, X.R.; Zhao, M.; Wang, L.J.; Li, W.; et al. Global prevalence of asymptomatic norovirus infection: A meta-analysis. EClinicalMedicine 2018, 2-3, 50-58. [CrossRef]

33. Chan, C.M.; Chan, C.W.; Ma, C.K.; Chan, H.B. Norovirus as cause of benign convulsion associated with gastro-enteritis. J. Paediatr. Child Health 2011, 47, 373-377. [CrossRef]

34. Chen, S.Y.; Tsai, C.N.; Lai, M.W.; Chen, C.Y.; Lin, K.L.; Lin, T.Y.; Chiu, C.H. Norovirus infection as a cause of diarrhea-associated benign infantile seizures. Clin. Infect. Dis. 2009, 48, 849-855. [CrossRef]

35. Hall, A.J.; Lopman, B.A.; Payne, D.C.; Patel, M.M.; Gastañaduy, P.A.; Vinjé, J.; Parashar, U.D. Norovirus disease in the United States. Emerg. Infect. Dis. 2013, 19, 1198-1205. [CrossRef]

36. Korea Disease Control and Provention Agency (KDCA). Infectious Diaseases Surveillance Yearbook; KDCA: Osong, Korea, 2019; pp. 28-30.

37. Gutiérrez-Aguirre, I.; Steyer, A.; Boben, J.; Gruden, K.; Poljšak-Prijatelj, M.; Ravnikar, M. Sensitive Detection of Multiple Rotavirus Genotypes with a Single Reverse Transcription-Real-Time Quantitative PCR Assay. J. Clin. Microbiol. 2008, 45, $2547-2554$. [CrossRef] [PubMed]

38. Soltan, M.A.; Tsai, Y.-L.; Lee, P.-Y.A.; Tsai, C.-F.; Chang, H.-F.G.; Wang, H.-T.T.; Wilkes, R.P. Comparison of electron microscopy, ELISA, real time RT-PCR and insulated isothermal RT-PCR for the detection of Rotavirus group A (RVA) in feces of different animal species. J. Virol. Methods 2016, 235, 99-104. [CrossRef] [PubMed]

39. Park, S.H.; Kim, Y.O.; Kim, H.K.; Kim, H.S.; Kim, B.Y.; Cheon, K.R.; Kim, M.J.; Kim, S.H.; Chung, J.K.; Woo, Y.J. Incidence of benign convulsions with mild gastroenteritis after introduction of rotavirus vaccine. Brain Dev. 2015, 37, 625-630. [CrossRef] [PubMed]

40. Cho, H.; Lee, H.; Kim, D.S.; Kim, H.M.; Kim, J.H.; Kim, A.Y.; Kang, H.Y. Socioeconomic impact of the rotavirus vaccine in Korea: Comparing the epidemiologic and economic characteristics of rotavirus gastroenteritis before and after the introduction of vaccines. Pediatr. Infect. Dis. J. 2020, 39, 460-465. [CrossRef]

41. Hung, J.J.; Wen, H.Y.; Yen, M.H.; Chen, H.W.; Yan, D.C.; Lin, K.L.; Lin, S.J.; Lin, T.Y.; Hsu, C.Y. Rotavirus gastroenteritis associated with afebrile convulsion in children: Clinical analysis of 40 cases. Chang Gung Med. J. 2003, 26, 254-259.

42. Hungerford, D.; Jere, K.C.; Bar-Zeev, N.; Harris, J.P.; Cunliffe, N.A.; Iturriza-Gómara, M. Epidemiology and genotype diversity of norovirus infections among children aged $<5$ years following rotavirus vaccine introduction in Blantyre, Malawi. J. Clin. Virol. 2020, 123, 104248. [CrossRef]

43. Kang, S.Y.; Lee, H.J.; Kim, S.H. Convulsions with noroviral gastroenteritis in children at a single center in Korea. Ann. Child Neurol. 2018, 26, 233-239. [CrossRef]

44. Jensen, F.E.; Baram, T.Z. Developmental seizures induced by common early-life insults: Short- and long-term effects on seizure susceptibility. Ment. Retard. Dev. Disabil. Res. Rev. 2000, 6, 253-257. [CrossRef]

45. Jonesteller, C.L.; Burnett, E.; Yen, C.; Tate, J.E.; Parashar, U.D. Effectiveness of Rotavirus Vaccination: A Systematic Review of the First Decade of Global Postlicensure Data, 2006-2016. JO Clin. Infect. Dis. 2017, 65, 840-850. [CrossRef]

46. Vesikari, T. Rotavirus vaccination: A concise review. Clin. Microbiol. Infect. 2012, 18, 57-63. [CrossRef] [PubMed]

47. Yoo, S.Y.; Kim, D.H.; Lee, Y.; Lee, G.H.; Ha, D.J.; Kwon, Y.S. Serum uric acid as a predictive factor for rotaviral or noroviral benign convulsions with mild gastroenteritis. Ann. Child Neurol. 2020, 28, 138-144. [CrossRef]

48. Sakai, Y.; Kira, R.; Torisu, H.; Yasumoto, S.; Saito, M.; Kusuhara, K.; Hara, T. Benign convulsion with mild gastroenteritis and benign familial infantile seizure. Epilepsy Res. 2006, 68, 269-271. [CrossRef] [PubMed]

49. Motoyama, M.; Ichiyama, T.; Matsushige, T.; Kajimoto, M.; Shiraishi, M.; Furukawa, S. Clinical characteristics of benign convulsions with rotavirus gastroenteritis. J. Child Neurol. 2009, 24, 557-561. [CrossRef]

50. Matsufuji, H.; Ichiyama, T.; Isumi, H.; Furukawa, S. Low-dose carbamazepine therapy for benign infantile convulsions. Brain Dev. 2005, 27, 554-557. [CrossRef]

51. Berkovic, S.F.; Harkin, L.; McMahon, J.M.; Pelekanos, J.T.; Zuberi, S.M.; Wirrell, E.C.; Gill, D.S.; Iona, X.; Mulley, J.C.; Scheffer, I.E De-novo mutations of the sodium channel gene SCN1A in alleged vaccine encephalopathy: A retrospective study. Lancet Neurol. 2006, 5, 488-492. [CrossRef]

52. Weng, W.C.; Hirose, S.; Lee, W.T. Benign convulsions with mild gastroenteritis: Is it associated with sodium channel gene SCN1A mutation? J. Child Neurol. 2010, 25, 1521-1524. [CrossRef] 